\title{
Relationship between chronic nasal obstruction and craniofacial growth: an experimental model
}

\author{
Emanuele Scarano a, Fabrizio Ottaviani a, Stefano Di Girolamo ${ }^{\text {a,* }}$, Alessandra Galli ${ }^{\text {a }}$, \\ Roberto Deli ${ }^{\text {b }}$, Gaetano Paludetti ${ }^{\text {a }}$ \\ a Institute of Otorhinolaryngology, Catholic University of the Sacred Heart, Largo Gemelli 8, 00168 Rome, Italy \\ ${ }^{\mathrm{b}}$ Institute of Odontoiatrics, Catholic University of the Sacred Heart, Rome, Italy
}

Received 14 January 1998; received in revised form 2 April 1998; accepted 5 April 1998

\begin{abstract}
The aim of this paper was to verify if the growth of the nasomaxillary complex can be influenced by a purely functional alteration such as nasal obstruction, which was induced experimentally in a genetically controlled animal model. Sixty albino rats were employed. Twenty of them had the right nostril occluded by a synthetic resin; another twenty had both nostrils occluded; the other 20 were taken as control group. When the growth was completed, the rats were sacrificed and cephalometric analysis was carried out. Both treated groups showed a statistically significant reduction in overall weight and height, in the vertical development of the nasomaxillary complex and in the skullbase longitudinal axis. After discussing the literature on the subject, the authors conclude that normal craniofacial growth in the rat must somehow depend on physiological nasal breathing, which should therefore be considered of crucial importance. (C) 1998 Elsevier Science Ireland Ltd. All rights reserved.
\end{abstract}

Keywords: Chronic nasal obstruction; Craniofacial growth; Nasomaxillary complex; Animal model; Wistar rats

\section{Introduction}

Hippocrates as early as in the 5th century B.C. first observed the consequences of oral breathing upon nasomaxillary growth in childhood [11]. Still, the complex mechanisms that rule growth in

\footnotetext{
* Corresponding author. Tel.: + 396 30154439; fax: + 396 3051343; e-mail: md0864@mclink.it
}

the craniofacial district have not yet been fully understood, neither has the role played by oral breathing.

Brodie [4] in 1941 first suggested that genetic inheritance was to be considered as the main factor influencing the growing tissues, while Sicher [22] added that such genetical control was active mainly upon the connective tissue lying inside joints. Scott [21] in 1955 stated that the 
cartilage instead was to be considered as the target of genetic influences, and that maxillary growth was guided mainly by the septum cartilagineum.

Later, after the introduction of new diagnostic tools, the importance of functional aspects has become more and more evident.

In 1969, Moss [16] suggested that neither the cartilage nor the sutures follow any growth pattern of their own but, on the contrary, that they adapt to the growing conditions of the surrounding tissues and structures. The osteo-cartilagineous complex should then be interpreted as a mere mechanical support and protective structure for the so-called 'functional matrices', i.e. the face and the brain.

Enlow [6,7] described three functional regions, which he called 'counterparts': the skullbase, the maxilla and the mandible. Each part of the skull grows harmonically to its skeletal counterparts, so that the growth of each counterpart is dependent on that of the other two. This revolutionary approach has been valued and confirmed by Petrovic [18], who stated that the growth of the different parts of the facial skeleton is constantly ruled and modified through a complex series of feed-back mechanisms, as in a cybernetic system.

From a clinical point of view, it is well known that chronic oral breathing in children, usually due to adenoid hypertrophy or chronic rhinitis, is associated with ogival palate and excessive development of the vertical axis of the facial skeleton (dolicocephalia or 'long face syndrome') $[10,13,23]$. Moreover, tonsillectomy and/or adenoidectomy are usually associated with an improvement in sleep quality and body weight in children [3].

Aim of our work was to verify if nasomaxillary growth can be modified by a purely functional alteration, i.e. nasal obstruction, which we produced experimentally in an animal model.

\section{Methods}

Sixty albino rats were enrolled, just after weaning was completed (28th day of life). They were divided into three groups: (a) control group (20 rats); (b) right nostril obstruction (by means of a synthetic resin called Xantopren ${ }^{\circledR}$ ) (20 rats); (c) both nostrils obstructed by Xantopren ${ }^{\circledR}$ (20 rats).

One hundred and twenty days later, after the rats had completed their development, they were all sacrificed by means of $10 \mathrm{cc}$ intracardiac Pentothal. The weight of all rats was recorded. Teleradiographs in both submento-vertex and latero-lateral projection were carried out by means of a craniostat as described in a previous paper [17]. Cephalometric analysis was carried out considering the following points:

\subsection{Submento-vertical projection (Fig. 1)}

I, superior interincisive point; A, most posterior point of the occipital bone; A-I line, through points $\mathrm{A}$ and $\mathrm{I}$, indicating the overall length of the skull; P, basis of the sphenoid bone; L1, most anterior and superior point in the malar process of the right maxilla; L2, most anterior and superior point in the malar process of the left maxilla; $\mathrm{O}$, intersection point of the premaxillary-palatal junction on the $\mathrm{A}-\mathrm{I}$ line; $\mathrm{X} 1$, intersection point between a straight line passing through point $\mathrm{P}$ and normal to the median plane, and the internal border of the right zygomatic arch; X2, intersection point between a straight line passing through point $\mathrm{P}$ and normal to the median plane, and the internal border of the left zygomatic arch; X1-X2 line, transversal development of the most posterior region of the fossa cranica media; L1-O line, medio-lateral development of ther right maxilla; L2-O line, medio-lateral development of ther left maxilla; L1-L2 line, overall development of both maxillae.

\subsection{Latero-lateral projection (Fig. 2)}

E, intersection between the frontal bone and the most superior and anterior point of the ethmoid; $\mathrm{U}$, intersection between the maxillary sinus and the distal surface of the third superior molar tooth; E-U line, overall height of the nasomaxillary complex.

All results were analyzed by means of Student's $t$-test and considered significant if $P<0.05$. 

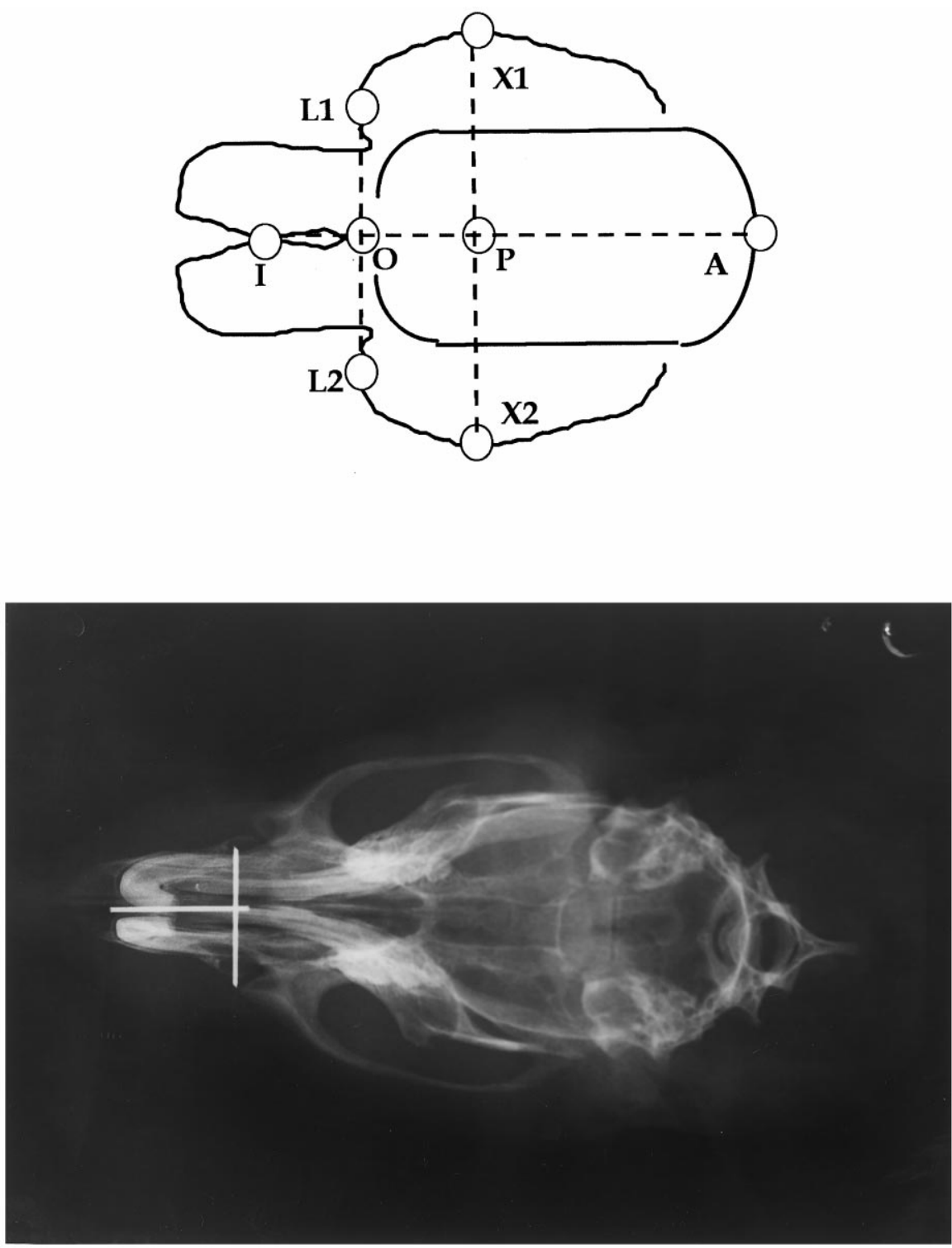

Fig. 1. Teleradiographs in submento-vertex projection (A) and drawing (B).

\section{Results Table 1}

A significant difference in the average weight was found in the treated groups in comparison with the control group at the 28th day of life: 600 $\mathrm{g}$ for control rats, $540 \mathrm{~g}$ for monolaterally occluded rats $(P<0.05)$ and $458 \mathrm{~g}$ for bilaterally occluded rats $(P<0.05)$.
The vertical development of the nasomaxillary complex (E-U line) resulted to be significantly reduced in both treated groups $(\mathrm{B}, \mathrm{C})$ if compared to the control group (A). In the latter, the average height of the nasomaxillary complex was in fact $1.71 \pm 0.02 \mathrm{~cm}$, while in group B it was $1.67 \pm$ $0.02 \mathrm{~cm}(P<0.001)$ and in group $\mathrm{C} 1.51 \pm 0.01$ $\mathrm{cm}(P<0.001)$. The difference in height proved 

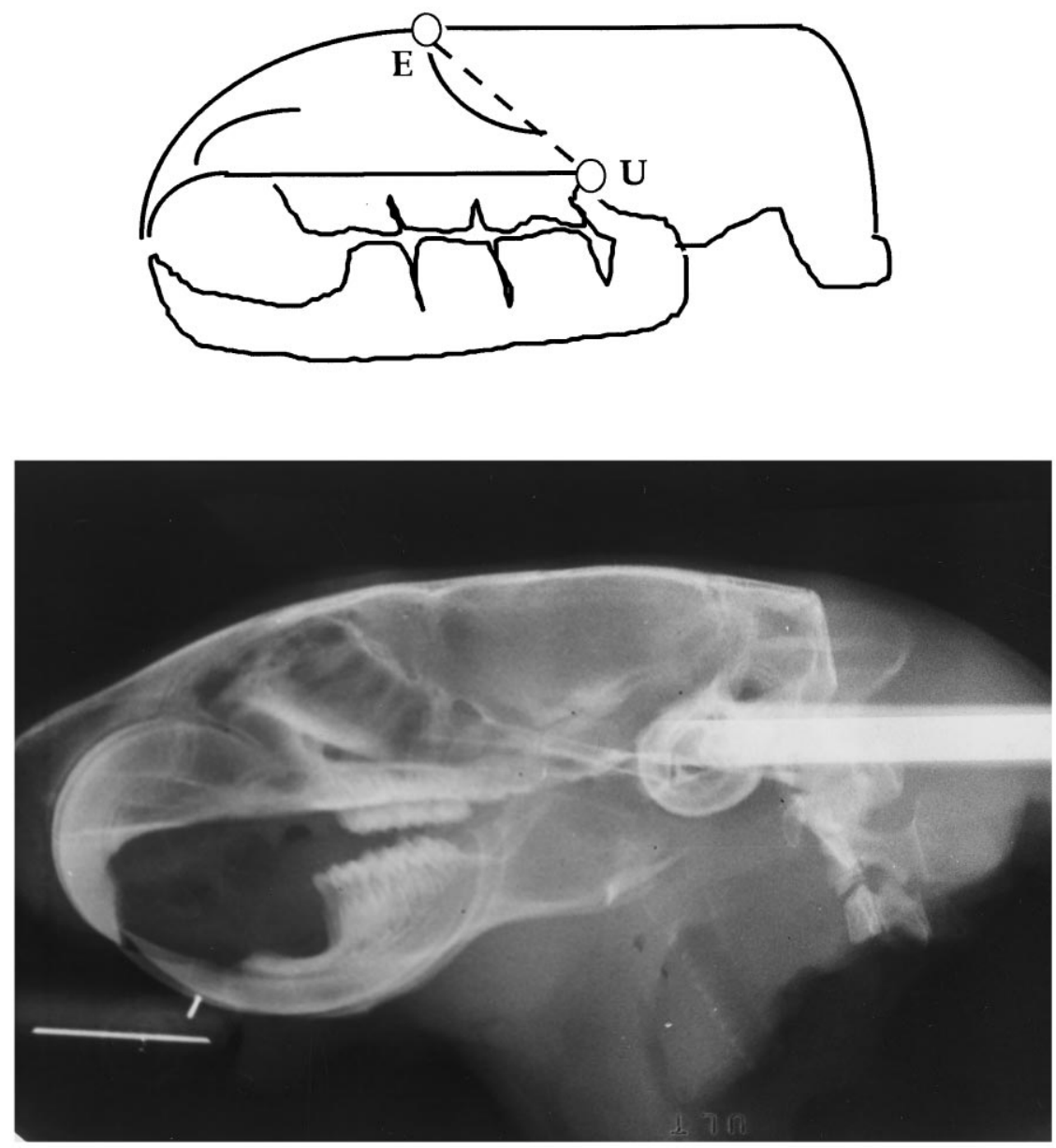

Fig. 2. Teleradiographs in latero-lateral projection (A) and drawing (B).

statistically significant also comparing group B with group $\mathrm{C}(P<0.001)$.

The same trend was found when measuring the longitudinal development of the skullbase (A-I line), which was on average $5.06 \pm 0.11 \mathrm{~cm}$ in group A, $4.93 \pm 0.12 \mathrm{~cm}$ in group B and $4.77 \pm$ $0.21 \mathrm{~cm}$ in group $\mathrm{C}$. The difference was statistically significant between groups $\mathrm{A}$ and $\mathrm{C}$, i.e. between controls and bilaterally occluded rats $(P<0.04)$, while between groups $\mathrm{A}$ and $\mathrm{B}$ the difference was still present but not significant $(P<0.06)$.

No differences were found for this parameter between groups $\mathrm{B}$ and $\mathrm{C}(P<0.1)$.

Considering the anterior development of the right maxilla ( $\mathrm{L} 1-\mathrm{O})$, significant data were found when comparing controls with both the other groups.

No significant difference was found between groups $\mathrm{B}$ and $\mathrm{C}$.

Considering instead the right transverse diameter $(1.21 \pm 0.02 \mathrm{~cm})$ in unilaterally treated rats (L2-O), it was significantly different from the other two groups $(P<0.01)$ (vs. $1.25 \pm 0.01$ in group $A$ and $1.30 \pm 0.03$ in group $C$ ).

A significant difference was found between the right and left sides only in group B, in which the diameter on the occluded side was decreased

As expected, no difference was found between the diameters ( $\mathrm{L} 1-\mathrm{O}$ and $\mathrm{L} 2-\mathrm{O}$ ) in groups $\mathrm{A}$ and $\mathrm{C}$, while a conspicuous asymmetry was recorded in unilaterally treated rats. In group B, in fact, an 
Table 1

Means, standard deviation and statistical significances in the three groups

\begin{tabular}{|c|c|c|c|c|}
\hline & Group A & Group B & Group C & Student's $t$-test \\
\hline Weight (g) & $600 \pm 20$ & $540 \pm 18$ & $458 \pm 13$ & $*, * *, * * *$ \\
\hline Length (A-I) & $5.06 \pm 0.11$ & $4.93 \pm 0.12$ & $4.77 \pm 0.21$ & $* *$ \\
\hline \multicolumn{5}{|l|}{ Width } \\
\hline $\mathrm{L} 1-\mathrm{O}$ & $1.26 \pm 0.01$ & $1.31 \pm 0.02$ & $1.32 \pm 0.07$ & $*, * *$ \\
\hline $\mathrm{X} 1-\mathrm{X} 2$ & $2.54 \pm 0.02$ & $2.57 \pm 0.05$ & $2.56 \pm 0.06$ & n.s. \\
\hline $\mathrm{X} 1-\mathrm{P}$ & $1.27 \pm 0.01$ & $1.30 \pm 0.03$ & $1.28 \pm 0.04$ & n.s. \\
\hline $\mathrm{X} 2-\mathrm{P}$ & $1.27 \pm 0.02$ & $1.27 \pm 0.01$ & $1.28 \pm 0.05$ & n.s. \\
\hline
\end{tabular}

*Significant difference between group $\mathrm{A}$ and $\mathrm{B}$; **significant difference between group $\mathrm{A}$ and $\mathrm{C}$; *** significant difference between group $\mathrm{B}$ and $\mathrm{C}$.

underdevelopment was observed on the side of occlusion (1.21 \pm 0.02$)$, and a overdevelopment $(1.31 \pm 0.02)$ on the opposite side. This trend may also explain the lack of difference of the total anterior transverse diameter $(\mathrm{L} 1-\mathrm{L} 2)$ between monolaterally treated animals and controls.

This diameter was significantly increased in group C $(2.62 \pm 0.01 \mathrm{~cm})$ if compared with $\mathrm{A}$ and B $\quad(2.51 \pm 0.02 \mathrm{~cm}$ and $2.52 \pm 0.04 \mathrm{~cm}$, respectively).

Nasal obstruction seems to have no role in the growth of the posterior transverse diameter (X1$\mathrm{X} 2$ ), both in uni- and bilaterally occluded rats.

\section{Discussion}

A normal craniofacial growth seems to depend on physiological nasal breathing, as shown by different clinical and experimental data $[8,24,27]$.

Besides clinical experience, a significant relationship has been reported between the width of the rhinopharyngeal airway, measured through teleradiography, and nasal resistance parameters, as measured through active anterior rhinomanometry [12,14,25].

Moreover, according to Dunn et al. [5], who performed cephalometry in 33 couples of homozygotic twins, there is an inverse proportion between the bi-gonial length and the anteroposterior width of the rhinopharynx. Such data were indirectly confirmed by clinical reports on patients with turbinate hypertrophy and children affected by perennial allergy $[1,2,19]$ and choanal atresia [20].

The influence of oral breathing has also been claimed to explain the posterior rotation of the mandible, as reported in children affected by adenoid hypertrophy [26].

An interesting experimental contribution regarding nasal obstruction and craniofacial growth, is that of Harvold et al. [9], in which a number of electromyographic, cephalometric and occlusal variations were reported in anthropomorphic monkeys after artificial nasal obstruction induced during early stages of development.

Similar findings were recently reported by Yamada et al. [28], whose work confirmed the observation of permanent craniofacial deformities after inducing nasal obstruction in young Macaca monkeys (before and during puberal development).

Our results are in agreement both with Harvold et al. [9] and Yamada et al. [28], showing a reduction in height of the maxilla. Yet, although Harvold's and Yamada's models seem particularly interesting as the animals used are phylogenetically close to humans, they are limited by the fact that genetic variability cannot be excluded. This is the reason why we used a genetically controlled model, so that the role played by functional factors could be enhanced. The importance of genetic control upon craniofacial growth is indirectly confirmed by the homogeneity of parameters found in group A. Of course, atten- 
tion must be paid in transferring these data to those of human development, because the growth patterns of each animal species are different: a vertical quadrangular shape is typical of humans and cats, a triangular shape of chimpanzees and rhesus monkeys, and a horizontal quadrangular shape of rats, rabbits and dogs [15]. However, our data seem to prove that nasal obstruction plays a direct influence on the growth of the skull, at least in the rat. In fact, a progressive decrease in height, width and length and also in overall weight was recorded proportionally to the entity of nasal obstruction, as shown by the maximum contraction of all values when bilateral occlusion had been carried out.

Such a reduction is only seen in the anterior nasomaxillary complex, while the data obtained for the posterior segment of the skull seem to exclude an influence of breathing patterns on the growth of such a segment of the skullbase. Therefore, the more conspicuous contraction of the anterior segment cannot be considered as a consequence of the general underdevelopment of the skeleton.

Interestingly, unilateral occlusion determines a homolateral contraction of the anterior transverse diameter ( 2 2-O), which seems to be compensated for by an 'expansion' of the functionally preserved side $(\mathrm{L} 1-\mathrm{O})$.

In conclusion, our work, although limited to an animal model, focuses the role that chronic nasal obstruction may play upon nasomaxillary growth patterns, if it occurs during development.

\section{References}

[1] D. Bresolin, G.G. Shapiro, P.A. Shapiro, M.K. Chapko, S.W. Dassel, Mouth breathing in allergic children: its relationship to dentofacial development, Am. J. Orthodont. 83 (1983) 334-340.

[2] D. Bresolin, G.G. Shapiro, P.A. Shapiro, S.W. Dassel, C.T. Furukawa, W.E. Pierson, M.K. Chapko, C.W. Bierman, Facial characteristics of children who breathe through the mouth, Pediatrics 73 (1984) 622-625.

[3] D. Breton, M.P. Morisseau-Durand, G. Cheron, Growth retardation and obstructive sleep apnea in infants, Arch. Fr. Pediatr. 50 (6) (1993) 493-496.

[4] A.G. Brodie, Behavior of normal and abnormal facial growth patterns, Am. J. Orthodont. Oral Surg. 27 (1941) $633-647$.
[5] G.F. Dunn, L.J. Green, J.J. Cunat, Relationship between variation of mandibular morphology and variation of nasopharyngeal airway size in monozygotic twins, Angle Orthodont. 43 (1973) 129-135.

[6] D.H. Enlow, Research on control on cranio-facial morphogenesis. State of the art, Am. J. Orthodont. 71 (1977) 509.

[7] D.H. Enlow, Handbook of Facial Growth, 2nd ed., WB Saunders, Philadelphia, 1982.

[8] B. Fricke, H.J. Gebert, R. Grabovski, A. Hasund, H.G. Serg, Nasal airway, lip competence and craniofacial morphology, Eur. J. Orthodont. 15 (1993) 297-304.

[9] E.P. Harvold, K. Vangervik, G. Chierici, B.S. Tomer, Primate experiments on oral respiration, Am. J. Orthodont. 79 (1981) 359-372.

[10] E. Hellsing, C.M. Forsberg, S. Linder-Aronson, A. Sheikhoeslam, Changes in postural EMG activity in the neck and masticatory muscles following obstruction of nasal airway, Eur. J. Orthodont. 8 (1986) 247-253.

[11] Hippocrates: Book V: 1, 2.

[12] H. Holmberg, S. Linder-Aronson, Cephalometric radiographs as a means of evaluating the capacity of the nasal and nasopharyngeal airway, Am. J. Orthodont. 76 (1979) 479-490.

[13] B.D. Jennings, W.L. Schlenker, P.J. Boyn, R.D. Walters, The effects of chronic abscence of active nasal respiration on the growth of the skull. Normal and abnormal bone growth, Bas. Clin. Res. 403 (1985) 12.

[14] S. Linder-Aronson, Adenoids - their effects on mode of breathing and nasal airflow and their relationship to characteristics of the facial skeleton and the dentition, Acta Otolaryngol. (1970) (Suppl.) 265.

[15] A. Losken, M.P. Mooney, M.I. Siegel, Comparative cephalometric study of nasal cavity growth patterns in seven animal models, Cleft Palate-Craniofac. J. 31 (1994) $17-23$.

[16] M.L. Moss, The primary role of functional matrices in facial growth, Am. J. Orthodont. 55 (1969) 566-572.

[17] G. Paludetti, G. Almadori, E. Scarano, R. Deli, A. Laneri de Bernart, M. Maurizi, Nasal obstruction and skullbase development: experimental study in the rat, Rhinology 33 (1995) $171-173$.

[18] A. Petrovic, Experimental and cybernetic approaches to the mechanism of action of functional appliances on mandibular growth, in: J.A. McNamara Jr., K.A. Ribbens (Eds.), Malocclusion and The Periodontium, Monograph 15. Craniofacial Growth Series, Ann Arbor, MI, Center for Human Growth and Development, University of Michigan, 1984.

[19] V. Sassouni, G.G. Friday, H. Shnorhokhian, Q. Beery, T.G. Zullo, D.L. Miller, S.M. Murphey, R.A. Landay, The influence of perennial allergic rhinitis on facial type and pilot study of the effect of allergy management on facial growth patterns, Ann. Allergy 54 (1985) 493-497.

[20] M.L. Schwartz, L. Savetsky, Choanal atresia: clinical features, surgical approach, and long-term follow-up, Laryngoscope 96 (1986) 1335-1339. 
[21] J.P. Scott, Craniofacial regions: contribution to the study of facial growth, Dent. Pract. 5 (1955) 208-213.

[22] H. Sicher, The growth of the mandible, Am. J. Orthodont. Oral. Surg. 33 (1947) 30-35.

[23] R.M. Smith, C. Gonzalez, The relationship between nasal obstruction and craniofacial growth, Pediatr. Clin. North Am. 36 (1989) 1423-1434.

[24] B. Solow, S. Siersbaek-Nielsen, E. Greve, Airway adequacy, head posture and craniofacial morphology, Am. J. Orthodont. 89 (1984) 214-223.

[25] H. Sorensen, B. Solow, E. Greve, Assessment of the nasopharyngeal airway, Acta Otolaryngol. 98 (1980) 227-
232.

[26] Y. Tosun, S. Tezcan, H.I. Erol, F. Flageul, Evaluation des paramètres cranio-faciaux chez les individus ayant des végétations adénoides, Rev. Orthop. Dentofaciale 27 (1993) 183-188.

[27] P. Vig, D. Sarver, D. Hall, D. Warren, Quantitative evaluation of nasal airflow in relation to facial morphology, Am. J. Orthodont. 79 (1981) 263-272.

[28] T. Yamada, K. Tanne, K. Miyamoto, K. Yamauchi, Influence of nasal respiratory obstruction on craniofacial growth in young Macaca fuscata monkeys, Am. J. Orthodont. Dentofacial Orthop. 111 (1997) 38-43. 